\title{
Duodenal Neuroendocrine Tumour Resection with a New Duodenal Full-Thickness Resection Device
}

\author{
João Cortez-Pinto ${ }^{a}$ Susana Mão de Ferro ${ }^{a}$ Joana Castela ${ }^{a} \quad$ Isabel Claro ${ }^{a}$ \\ Paula Chaves $^{\mathrm{b}}$ António Dias Pereira ${ }^{\mathrm{a}}$ \\ a Serviço de Gastrenterologia, Instituto Português de Oncologia de Lisboa Francisco Gentil (IPOLFG) EPE, \\ Lisbon, Portugal; 'b Serviço de Anatomia Patológica, Instituto Português de Oncologia de Lisboa Francisco Gentil \\ (IPOLFG) EPE, Lisbon, Portugal
}

\section{Keywords}

Endoscopy · Duodenum · Neuroendocrine tumour .

Full-thickness resection

\section{Ressecção endoscópica de tumor neuroendócrino duodenal com um novo dispositivo de ressecção transmural}

\section{Palavras Chave}

Endoscopia · Duodeno - Tumor neuroendócrino .

Ressecção transmural

Most well-differentiated, non-functional duodenal neuroendocrine tumours (NETs) limited to the mucosa/ submucosa can be treated effectively with endoscopic resection [1]. A full-thickness resection device (FTRD; Ovesco Endoscopy ${ }^{\circledR}$ ) enables endoscopic transmural resection of suitable lesions with a fast minimally invasive technique [2]. A colonic FTRD was used for duodenal lesions as an "off-label" indication with good clinical outcomes and a complication rate comparable to duodenal

\section{KARGER}

E-Mail karger@karger.com www.karger.com/pjg (c) 2020 Sociedade Portuguesa de Gastrenterologia Published by S. Karger AG, Basel

Karcer

Upen access

This article is licensed under the Creative Commons AttributionNonCommercial-NoDerivatives 4.0 International License (CC BYNC-ND) (http://www.karger.com/Services/OpenAccessLicense). Usage and distribution for commercial purposes as well as any distribution of modified material requires written permission. endoscopic mucosal resection [3]. A duodenal FTRD (dFTRD) with smaller diameter (19.5 vs. $21 \mathrm{~mm}$ ), balloonassisted insertion and less clip interdental space was developed allowing easier upper oesophageal sphincter passage and minimising bleeding risk.

We describe a 74 -year-old male with a $10-\mathrm{mm}$ postpyloric bulbar submucosal lesion (Fig. 1, 2) with biopsies showing a well-differentiated NET. Endoscopic ultrasonography showed a submucosal lesion. Endoscopic ultrasonography and 68-Ga DOTA-NOC PET/CT displayed no lymph node involvement or distant metastases. An attempt to resect with band ligation endoscopic mucosal resection failed because of an absence of aspiration into the cap. Transmural resection with the d-FTRD was scheduled in the operating room under general anaesthesia. Lesion borders were marked with argon plasma coagulation. Upper oesophageal sphincter dilation was performed with Savary-Gilliard bougie dilator (15-18 mm) allowing d-FTRD insertion. A paediatric colonoscope (outer diameter: $11.8 \mathrm{~mm}$; working channel calibre: 3.2 $\mathrm{mm}$ ) was then advanced to the duodenum with the dFTRD attached. Traction of the lesion to the cap with the grasper and slight aspiration were done, followed by overthe-scope clip release (d-FTRD clip). Aspiration was nec- 


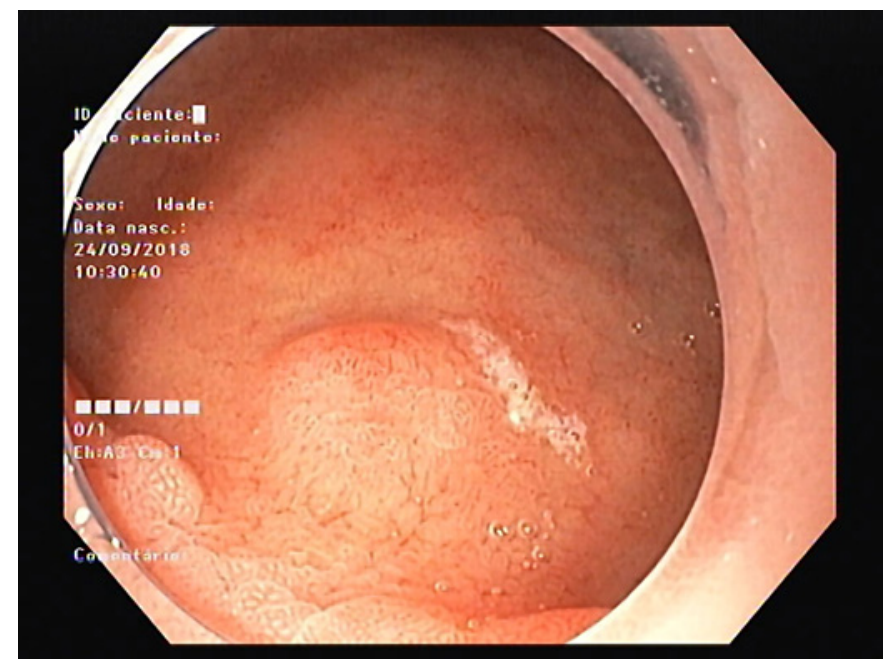

Fig. 1. Lesion in white-light endoscopy.

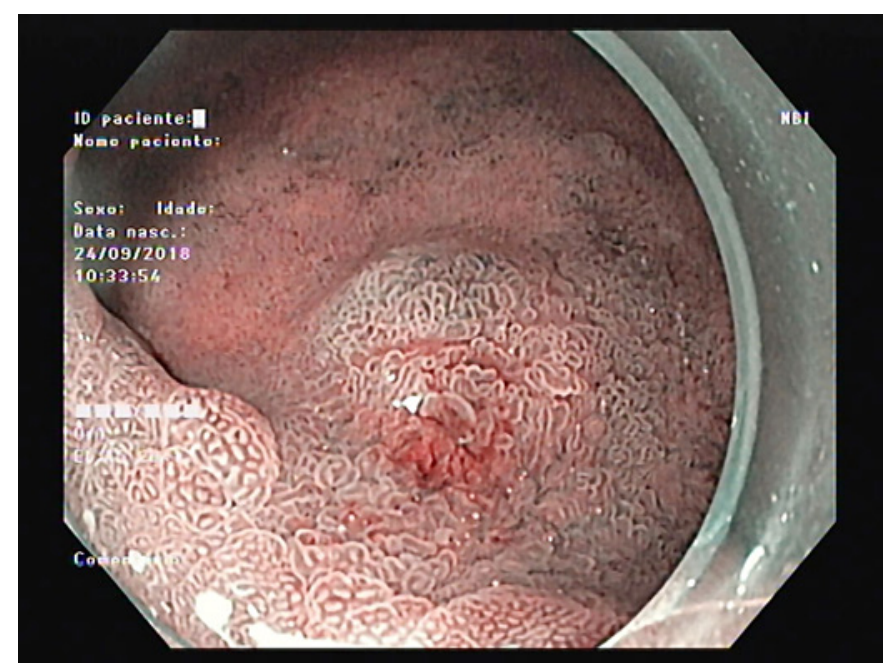

Fig. 2. Lesion in narrow-band image.

essary because of insufficient traction with the grasper. Due to a mucosal tear, the lesion was released from the grasping forceps after clip deployment (online suppl. Video; see www.karger.com/doi/10.1159/000505072 for all online suppl. material). Therefore, secondary resection with a conventional snare was performed (Fig. 3). There were no immediate or delayed complications. Histology showed a NET G1 ( $<3$ mitosis/10 high power field, $\mathrm{Ki} 67<3 \%$ ) with infiltration of the muscularis propria in a transmural specimen. There was no lymphatic or perineural invasion. The lateral margin of the lesion was coincident with the resection margin. After multidisci-

New Duodenal Full-Thickness Resection Device

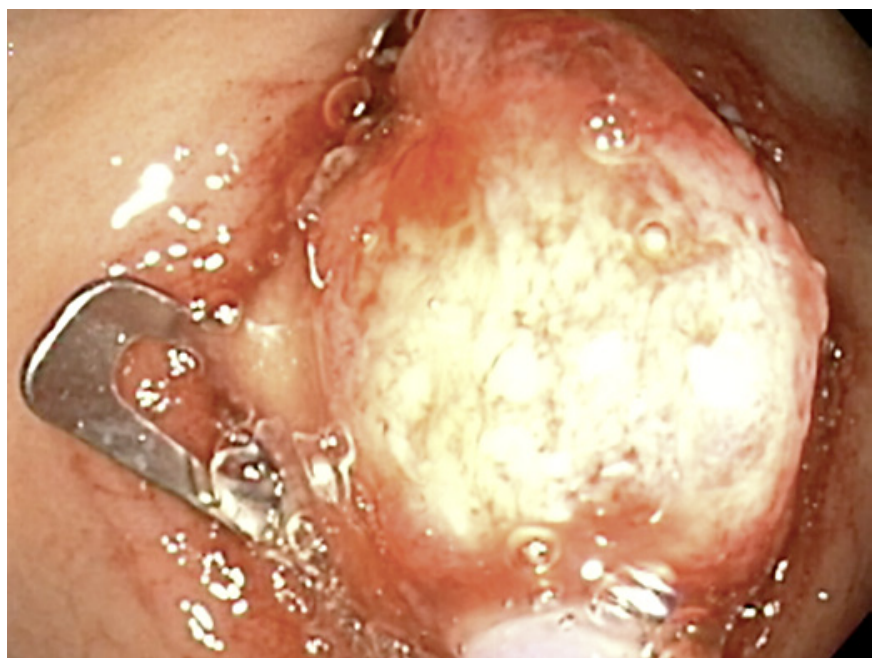

Fig. 3. Pseudo-polyp resection.

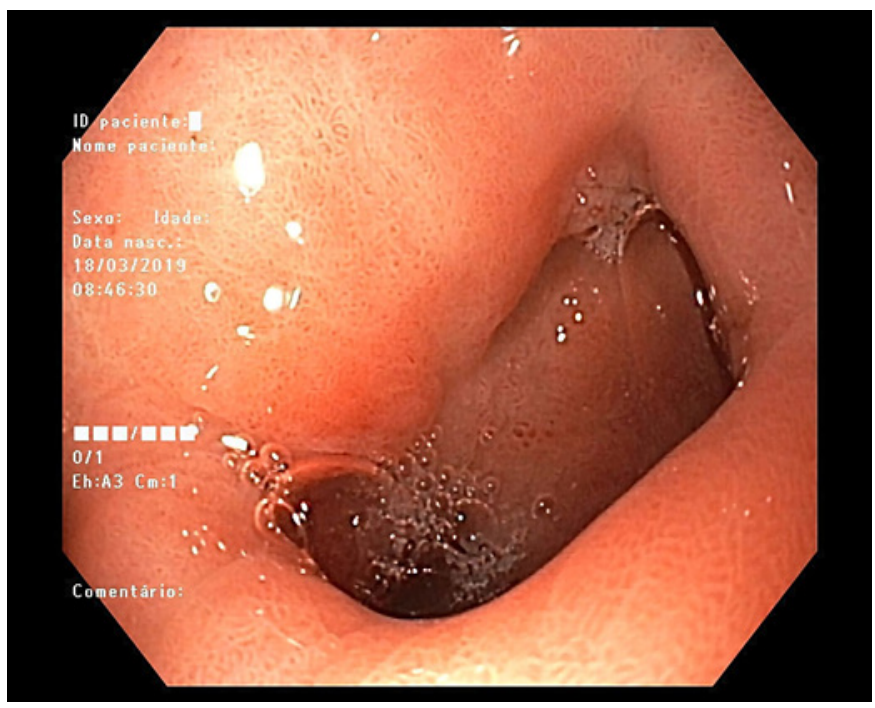

Fig. 4. Scar in 4-month re-evaluation.

plinary team discussion, surveillance was proposed. At 4- and 12-months' follow-up, there was no endoscopic residual lesion (Fig. 4) and the histology of the scar presented reparative alterations. d-FTRD is a new device that should be considered for the resection of subepithelial or non-lifting epithelial duodenal lesions.

\section{Statement of Ethics}

The study was reviewed and approved for publication by our Institutional Reviewer. 
Disclosure Statement

All the authors have no conflict of interest related to the article.

\section{Funding Sources}

This research received no specific grant from any funding agency in the public, commercial, or not-for-profit sectors.
References

1 Kim SH, Park CH, Ki HS, Jun CH, Park SY, Kim HS, et al. Endoscopic treatment of duodenal neuroendocrine tumors. Clin Endosc. 2013 Nov;46(6):656-661.

2 Albrecht H, Raithel M, Braun A, Nagel A, Stegmaier A, Utpatel K, et al. Endoscopic fullthickness resection (EFTR) in the lower gastrointestinal tract. Tech Coloproctol. 2019 Oct;23(10):957-63.

3 Bauder M, Schmidt A, Caca K. Endoscopic full-thickness resection of duodenal lesions-a retrospective analysis of 20 FTRD cases. United European Gastroenterol J. 2018 Aug;6(7): 1015-21. 